\title{
Laboratory Analysis of Polymer Thin Films for Planetary Balloons and Gossamer Structures
}

\author{
Jerry Sterling ${ }^{*}$ and Debora A. Fairbrother ${ }^{\dagger}$ \\ NASA Goddard Space Flight Center, Wallops Flight Facility, Wallops Island, VA 23337
}

\begin{abstract}
Commercially available polymer thin films with thickness of 15 microns or less were evaluated for potential application as the gas envelope material of balloons and other inflated vehicles. Films on this thickness scale are of interest for Earth and Mars ballooning as well as many gossamer space structures. Due to the uniqueness of these missions relative to typical uses of these materials, application-specific materials properties measurements were made. We evaluated numerous polymer chemistries, plus a few variations within one chemistry. The data show that there are often trade-offs among the different materials, such as with polyesters and polyimides having greater stiffness (modulus) but lower tear propagation resistance than polyethylene. Sections of polyethylene films can be joined by heat sealing, while adhesives and their accompanying mass penalty must be used with polyesters and polyimides. When the analysis temperature is reduced to $190 \mathrm{~K}$, polyethylenes display dramatically increased stiffness and yield point, while the increase for other materials is more modest. The data also show that manufacturing processes can significantly affect film properties. To emphasize the need for application-specific properties assessment, we discuss two recent applications using these materials.
\end{abstract}

\section{Introduction}

T HE Scientific Balloon Research and Development Laboratory at NASA Goddard Space Flight Center's Wallops Flight Facility has begun evaluating polymer thin films for potential application as the gas envelope material of balloons and airships for planetary exploration. These efforts are secondary and complementary to the Lab's core mission of supporting technology development for terrestrial applications. Environments of current interest include those of Mars, Venus, and Titan, and thereby span a very wide range of temperatures, pressures, chemical makeup, etc. These environments, especially the low temperature ones, have some commonality with those of gossamer space structures, and thus we hope our work will benefit other projects. As film and polymer manufacturers rarely report evaluation of materials for application in these or similar environments, measurement and evaluation must be undertaken by the end-users themselves. The design of a lightweight, inflatable structure for transporting scientific instrumentation is a great challenge, whether for terrestrial use or otherwise. Careful evaluation of candidate materials will facilitate structural design, while design innovation encourages the development of new materials.

A comparison of the approximate flight environments of interest is presented in Table 1. Even for terrestrial scientific balloon flights, for which conditions at $30 \mathrm{~km}(100,000 \mathrm{ft}$.) altitude are given, materials evaluation at standard laboratory conditions is rarely applicable. While the environments of Mars, Titan, and Earth are mainly chemically benign to many polymers, their low temperatures present great challenge to material performance. For Venus, not only is the high temperature a concern, but the chemical makeup of the atmosphere is also deleterious to the performance of many polymers. In this paper, and the table of environments, we have omitted some potentially important aspects, such as radiation effects, because not all gossamer applications will be concerned with them.

We focus below on measurement techniques and philosophies, as well as material performance trends. The data show that there are often trade-offs among the material properties, such weight (density), stiffness (modulus), tear propagation resistance, and toughness. These properties also typically change with temperature, but the extent of change is not uniform across different materials. Manufacturing issues such as joining and operational issues such as packing and unpacking are also concerns, although those are only qualitatively discussed in the present work.

\footnotetext{
* Materials Engineer, Balloon R\&D Laboratory, Jerry.Sterling@ nasa.gov. Member.

Balloon Technology Manager, Balloon Program Office, Debora.A.Fairbrother@nasa.gov. Senior Member.
} 
Table 1: Approximate environments of potential ballooning missions.

*Conditions of typical flight altitude ( $30 \mathrm{~km}, 100000 \mathrm{ft.}$, for Earth).

\begin{tabular}{|c|c|c|c|}
\hline & $\begin{array}{c}\text { Temperature } \\
\text { (Kelvin) }\end{array}$ & $\begin{array}{c}\text { Pressure } \\
\text { (Bar) }\end{array}$ & $\begin{array}{c}\text { Atmospheric } \\
\text { Chemistry }\end{array}$ \\
\hline Earth* & $180-250$ & 0.1 & Nitrogen, Oxygen \\
\hline Mars & $200-250$ & 0.01 & Carbon dioxide, Nitrogen, Argon \\
\hline Titan & $60-120$ & $0.1-1$ & Nitrogen, Methane, Argon \\
\hline Venus & $350-750$ & $1-10$ & Carbon dioxide, Nitrogen, Sulfuric acid \\
\hline
\end{tabular}

\section{Materials}

The NASA Balloon Program focuses on commercially available films to help control costs and minimize production issues such as raw material availability. Additionally, the joining methods for commercial films are generally better understood than for newly-developed materials. We evaluated the grades of each type of film that are most likely to perform well for our nearest-term applications, Mars and Earth stratospheric ballooning.

This work describes our measurements and analyses of some commercially available films with thickness of 15 microns (nominally $0.5 \mathrm{mil}$ ) or less. Films on this thickness scale are of interest for Mars ballooning as well as many gossamer space structures, although for Venus or Titan ballooning missions, substantially thicker material may be considered. Film thickness is a concern because balloon mass is a significant component of overall system mass, which is a primary design constraint along with things like desired altitude and altitude fluctuation tolerance.

The two primary materials used in scientific ballooning are polyethylene and polyester. NASA's large stratospheric ballooning missions typically use linear low-density polyethylene (LLDPE), while the flight experience with pressurized balloons of more modest size is primarily with polyethylene terephthalate (PET) film. Therefore, we use these two types of material as a starting point and expand to other promising materials. Polyethylene naphthalate (PEN) film has a molecular structure similar to PET, but the manufacturer claims performance enhancements that may benefit our application types. These films are primarily used as packaging materials, and another widely-used packaging material class, polyamides, is included because the manufacturer's information suggests potential applicability to our missions. Polyimides are favored in gossamer spacecraft applications due to space durability, which is not evaluated in the present work, so two polyimides were also evaluated for our applications.

During the manufacture of polymer resins and films, the properties of the final product can be influenced significantly by numerous manufacturing variables, such as polymerization extent, copolymerization, use of plasticizers or other additives, coextrusion, lamination, and coating. To evaluate some of these effects for polyethylene, we have compared many combinations of resins, additives, and film-making parameters, a selection of which are included in this paper. Coex $\mathrm{Z}$ is made from the same resin as the single-layer LLDPE, but has a 3-layer coextruded construction with the layers sequentially having thickness $20 \%, 60 \%$, and $20 \%$ of the total. Coex $\# 2$ and Coex \#5 are also 3-layer coextrusions, but have uniformly-distributed thickness among the layers $(33 \%, 33 \%, 33 \%)$. Coex \#5 uses an alternate resin, Exceed 1012CA, for all layers, while Coex \#2 uses the alternate resin only for the middle layer.

\section{Methods}

Our test methods follow as closely as practical the guidelines of the American Society for Testing and Materials (ASTM). In general, the principle to test polymer materials in conditions similar to the intended application ${ }^{1,2}$ is considered paramount to broad industry guidelines, such as ASTM, that are intended to facilitate communication among seller and purchaser rather than determine application-specific performance parameters. Many application environments dictate the use of non-standard materials evaluation due to their uniqueness. Stratospheric and planetary balloons and gossamer space structures must perform effectively in environments that are unique relative to the typical application of polymer thin films, e.g. packaging for consumer goods.

One such unique test is the cold brittleness (CB) test that has been included in evaluation of films for scientific balloons for decades. ${ }^{3}$ It determines the temperature $( \pm 2 \mathrm{~K})$ at which a transition from ductile to brittle behavior is observed in a dynamic impact test using a falling steel sphere. Although polymer engineers typically investigate such transitions via differential scanning calorimetry (DSC) or other thermal analysis techniques, ${ }^{1}$ the heritage of the $\mathrm{CB}$ test is important in determining the reliability metrics of ballooning missions. Typically, polyethylene balloon films show such a transition near $175 \mathrm{~K}$, a temperature somewhat colder than what stratospheric balloons are likely 
to encounter. The ductility of polyethylene is one of its most attractive features, and loss of that property could prove catastrophic. The CB test is included in the present work because the existence of any dramatic change in properties occurring between the environment in which we manufacture a structure and that in which it is to perform will dictate material selection. For the same reason, other common materials analyses, such as uniaxial tensile tests, are performed at various relevant temperatures.

The uniaxial tensile properties measurements are done on a servo-mechanical universal testing machine and follows ASTM D882 ${ }^{4}$ in spirit, although the specimen gauge length and extension rate have been chosen to suit our needs. Specimens with $25.4 \mathrm{~mm}$ width, $50.8 \mathrm{~mm}$ gauge length (grip separation), and $100 \mathrm{~mm}$ minimum overall length are tested at $50.8 \mathrm{~mm} / \mathrm{min}$ extension rate as measured by crosshead displacement. This gauge length and extension rate allows most materials to be pulled to failure inside the environmental chamber. The recorded yield stress corresponds to the point at which the stress-strain curve slope decreases below $20 \%$ of the maximum slope. The reported modulus is the greatest slope in the tensile curve prior to the yield point. Properties are measured in machine direction (MD, primary manufacturing axis) and transverse direction (TD, perpendicular to and across the primary manufacturing axis). Additionally, for some applications the tensile properties on the bias (45-degree angle between MD and TD) are important, although those measurements were not completed for the present work.

Film thickness is measured at 10 points approximately equally spaced along the length of each of four full-width TD strips, using a pneumatic gauge stand and digital comparator. The values stated below are therefore the averages of 40 measurements for each film. Additionally, the thickness of each specimen used for tensile experiments was measured in 3-5 places to ensure accurate properties reporting in stress units. The areal weight for each film was determined by individually weighing a minimum of three specimens that were each cut using a $0.25 \mathrm{~m}^{2}$ template, and as reported is scaled to $12.7 \mu \mathrm{m}(0.5 \mathrm{mil})$ to facilitate comparison. The Elmendorf tear test (ASTM D1922), ${ }^{5}$ which measures the dynamic resistance to propagation of an existing, standard tear, identifies films which might be prone to catastrophic failure due to minimal damage. The pendulum impact test (ASTM D3420), ${ }^{6}$ which measures the dynamic resistance to initiation and propagation of a failure due to an applied force using a cone-shaped striker ( $0.4 \mathrm{~mm}$ nominal diameter), provides another measure of film resiliency.

\section{Results and Discussion}

Test results are presented in Table 2. Comparing the measurements at $190 \mathrm{~K}$ and $300 \mathrm{~K}$ illuminates the effect of temperature on properties. The film orientation also has a strong effect on some properties in some films. Due to tensile instrument limitations, the more ductile films (LLDPE) were not deformed to failure at the low temperature, which invalidates the quantification of toughness, so the stated values reflect energy absorbed up to instrument limitation and imply the true toughness value will be greater than or equal to that stated. Any material with an embrittlement transition above the anticipated operating temperature is considered inappropriate for balloon construction, although other applications may have different criteria. Therefore, study of the polyamides was halted once their brittleness at $163-213 \mathrm{~K}$ was exposed by the $\mathrm{CB}$ test.

The data for PET and PEN reflect their chemical and structural similarity. A decision to use one over the other might reasonably be based on non-technical factors such as cost and availability. The polyimide properties are also similar to PET and PEN. None of these three material types is resistant to crack propagation erupting from minor damage, as reflected in the impact resistance and tear propagation resistance data. This is one of the primary reasons the NASA Balloon Program emphasizes polyethylene for its very large stratospheric balloons. Although LLDPE deforms rapidly due to low stress, i.e., it has a low modulus, it is very resistant to the evolution of catastrophic damage. It is interesting to note that although each material studied becomes stiffer and increases in yield stress at the lower temperature, the increases are more dramatic for the polyethylene. Additionally, the toughness of polyethylene increases at the lower temperature, while for the other materials it decreases.

Table 3 shows our comparison of three different three-layer coextrusions of linear low density polyethylene (LLDPE) that represent a larger study of coextrusions recently undertaken in our lab. The data from the single-layer LLDPE film from Table 2 is included for reference. LLDPEs are traditionally used by the NASA Balloon Program for terrestrial balloons of a variety types and sizes. These films have strong potential for use in a Mars superpressure balloon of lobed design, and were assembled from readily available commercial polymer resins by a contracted manufacturer. The combination of multiple layers in a coextrusion facilitates improved thickness control and reduces the effect of manufacturing defects such as pinholes, while avoiding the mass penalty of lamination adhesives. In addition, the toughness and yield stress appear to be improved by coextrusion. The alternate resin, which composes the entirely Coex \#5, appears to decrease the modulus and tear propagation resistance. The data for Coex $\# 2$ suggests that combining different resins in a layer-by-layer fashion is not beneficial. 
Table 2: Properties of different film types.

The use of trade names does not constitute an endorsement of such products or manufacturers, either expressed or implied, by NASA.

*Toughness value is not quantitative as discussed in the text.

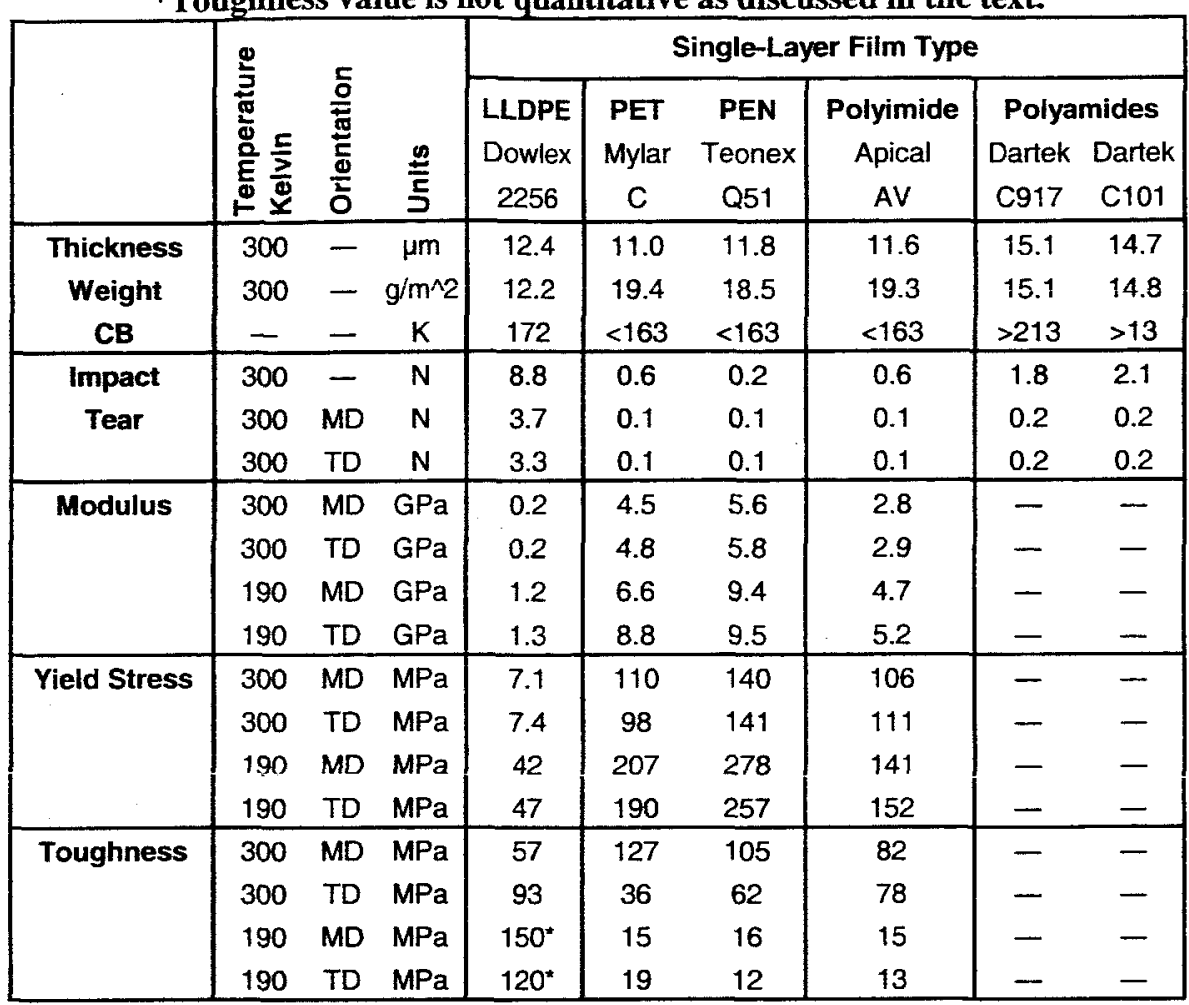

Table 3: Effect of construction on film properties.

*Toughness value is not quantitative as discussed in the text.

\begin{tabular}{|c|c|c|c|c|c|c|c|}
\hline & \multirow{3}{*}{ 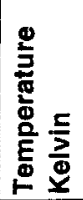 } & \multirow{3}{*}{ 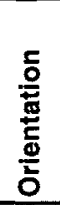 } & \multirow{3}{*}{$\stackrel{\stackrel{n}{E}}{5}$} & \multicolumn{4}{|c|}{$\begin{array}{c}\text { Film Construction } \\
\text { LLDPE Resins }\end{array}$} \\
\hline & & & & \multirow{2}{*}{$\begin{array}{l}\text { Single- } \\
\text { Layer }\end{array}$} & \multicolumn{3}{|c|}{ Coextrusions } \\
\hline & & & & & $\mathbf{z}$ & \#5 & \# 2 \\
\hline Thickness & 300 & - & $\mu \mathrm{m}$ & 12.4 & 13.2 & 12.8 & 12.4 \\
\hline Weight & 300 & - & $g / m^{\wedge} 2$ & 12.2 & 11.8 & 12.6 & 12.2 \\
\hline CB & - & - & $K$ & 172 & 178 & 178 & 167 \\
\hline Impact & 300 & - & $N$ & 8.8 & 8.5 & 8.4 & 10.3 \\
\hline \multirow[t]{2}{*}{ Tear } & 300 & MD & $N$ & 3.7 & 2.5 & 1.1 & 0.9 \\
\hline & 300 & $\mathrm{TD}$ & $\mathrm{N}$ & 3.3 & 4.9 & 3.0 & 1.7 \\
\hline \multirow[t]{4}{*}{ Modulus } & 300 & MD & $\mathrm{GPa}$ & 0.2 & 0.19 & 0.17 & 0.08 \\
\hline & 300 & TD & $\mathrm{GPa}$ & 0.2 & 0.16 & 0.13 & 0.08 \\
\hline & 190 & MD & $\mathrm{GPa}$ & 1.2 & 1.6 & 1.2 & 1.1 \\
\hline & 190 & TD & $\mathrm{GPa}$ & 1.3 & 1.4 & 1.2 & 0.9 \\
\hline \multirow[t]{4}{*}{ Yield Stress } & 300 & MD & $\mathrm{MPa}$ & 7.1 & 11.2 & 11.0 & 7.3 \\
\hline & 300 & TD & $\mathrm{MPa}$ & 7.4 & 11.1 & 7.7 & 6.1 \\
\hline & 190 & MD & $\mathrm{MPa}$ & 42 & 44 & 53 & 43 \\
\hline & 190 & TD & $\mathrm{MPa}$ & 47 & 49 & 65 & 48 \\
\hline \multirow[t]{4}{*}{ Toughness } & 300 & $M D$ & $\mathrm{MPa}$ & 57 & 97 & 90 & 71 \\
\hline & 300 & TD & $\mathrm{MPa}$ & 93 & 103 & 132 & 27 \\
\hline & 190 & $M D$ & $\mathrm{MPa}$ & $150^{*}$ & $140^{*}$ & $180^{*}$ & 17 \\
\hline & 190 & TD & $\mathrm{MPa}$ & $120^{*}$ & $210^{*}$ & $200^{*}$ & 12 \\
\hline
\end{tabular}




\section{Applications}

The collection of data without a specific mission rarely happens. Above, we discussed general mission types in terms of the effects of the environments on the materials. However, there have been two recent missions that benefited from the type of materials assessment outlined in this paper and that generated some of the information presented above. Those two missions are described below with particular emphasis on the materials assessment.

\section{A. Extreme Altitude Terrestrial Balloon}

In 1992, NASA established standard balloons to be flown by the Scientific Balloon Program to reduce design costs and improve reliability metrics. ${ }^{7}$ The NASA standard balloons followed an established design criterion and their sizes were chosen in consideration of the payload and altitude ranges of typical science payloads. Balloon volumes of $0.11,0.33,0.83$, and 1.11 million cubic meters, $\mathrm{mcm}(4.00,11.82,29.47$, and 39.57 million cubic feet, MCF) were established as the standards. Their capabilities ranges are shown in Figure 1 . These balloons all use 20 micron (0.8 mil) single-layer LLDPE film that is very similar to the LLDPE single-layer film discussed above. When thicknesses greater than 20 micron were required, such as in the top portion of the balloon to accommodate the additional forces occurring during launch, additional layers of 20 micron film was used.

Recently, a new balloon was designed in response to a science requirement to reach higher altitude than obtainable with any of the current standard balloons. ${ }^{8,9}$ To reach the load-altitude region desired by the science, it was necessary to reduce system mass in every way possible and therefore thinner balloon film was explored. Film half the current standard thickness was acceptable from a strength standpoint and could be handled appropriately by the fabricator without concem of handiling damage, and so the shell of the balloon was designed to be 10 micron $(0.4$ mil) thick three-layer coextruded LLDPE. The advantages of the coextruded construction discussed above led to the decision to move away from the single-layer construction used in the standard balloons.

The balloon had inflated dimensions of 130.7 meters ( 428.7 feet) high by 162.8 meters ( 534.2 feet) in diameter with an inflated volume of 1.7 million cubic meters (59.84 million cubic feet). ${ }^{8}$ It is often referred to as the "Big 60 ". While the gas envelope, or shell was the 10 micron LLDPE coextrusion, there were two additional layers of threelayer coextruded LLDPE in the top portion of the balloon of 13 microns $(0.52 \mathrm{mil})$ each to handle the launch stresses. This film is Coex $\mathrm{Z}$ discussed above. The balloon weighed $1248.3 \mathrm{~kg}$ (2752 pounds) and lifted a suspended weight of $701.3 \mathrm{~kg}$ (1546 pounds). The science instrument weighed $205 \mathrm{~kg}$ (452 pound). The balloon was launched on 26 August 2002 from Lynn Lake, MB, Canada. The total flight time was 22 hours and 22 minutes with a maximum altitude of $48.8 \mathrm{~km}(160,300 \mathrm{feet})$. This was the largest volume balloon ever flown and expands the load-altitude capability available with scientific balloons.

\section{B. Aerially-Deployed, Pressurized Mars Balloon}

Another application that requires a thin film for the construction of the balloon is for floating in the Martian atmosphere. An aerial vehicle at Mars will provide better coverage of the planet than the current rovers as well as better spatial resolution than available from orbiters. In consideration of flying during day-night cycles, a pressurized balloon system is desired. There are two different designs currently under consideration: a spherical balloon, which requires a high strength to weight material, and a lobed or pumpkin-shaped balloon, which requires high strength tendons. ${ }^{10}$

The scenario for a Mars balloon mission is for a packed balloon to be flown in a spacecraft to Mars and then aerially deployed and inflated while descending on a parachute. The deployment and aerodynamic forces of this process must be taken into consideration in the balloon designs. Success hinges on the balloon being able to withstand six months in a tightly packed state, deploy completely while descending on a parachute, and then pressurize to the designed level.

The spherical balloon under consideration is approximately 10 meters in diameter and is constructed of 12 micron $(0.5$ mil $)$ thick PET. This high stiffness film has the strength required to react the differential pressure in the structure but is sensitive to damage and tear propagation. Numerous balloons have been destroyed during aerial deployment and inflation tests.

The pumpkin balloon under consideration for Mars is 11.3 meters in diameter by 6.8 meters high. The shell material for this balloon is 12 micron ( $0.5 \mathrm{mil})$ thick coextruded LLDPE, while the high strength tendon member is poly(p-phenylene-2,6-benzobisozazole) (PBO). While the pumpkin balloon will be slightly heavier than the sphere, the strength requirements of the shell film are reduced compared to an equivalent volume sphere. This allows the tougher LLDPE film to be used in this balloon design. 


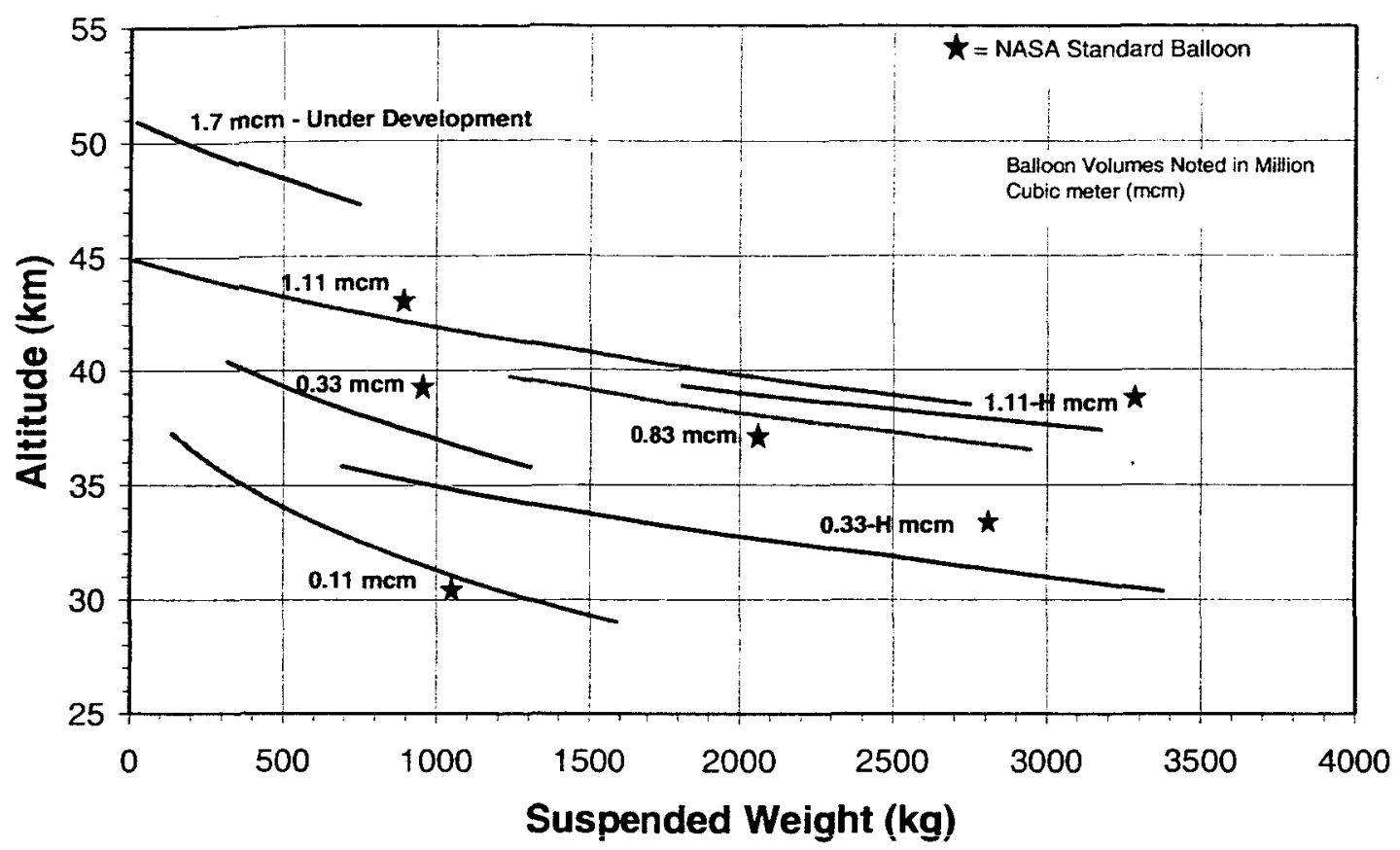

Figure 1: NASA Scientific Balloon Capabilities.

There is a clear trade-off between balloon designs and materials for construction. The stresses in the spherical balloon are greater, requiring a higher strength film. The drawback with a higher strength film is the lower impact and tear resistance. While the pumpkin balloon design has lower film strength requirements, the material must not become brittle in the Martian atmosphere at $153 \mathrm{~K}$. These balloon designs remain under development, with potential launch as early as 2011 .

\section{Conclusion}

The balloon design problems discussed illuminate the importance of proper material selection to mission success. The films compared in this work show that even within a single polymer chemistry, a range of mechanical properties is attainable. Therefore, given the number and range of available chemistries, combined with grade variations within a particular chemistry and properties control via additives and processing conditions, optimization of a design concept for a planetary balloon or gossamer structure must necessarily include evaluation of a variety of candidate materials.

\section{Acknowledgments}

This work was made possible by the hard work and dedication of the NASA Balloon R\&D Laboratory technicians who prepared the material specimens and conducted the experiments. Funding for this work was provided by the NASA Balloon Program Office. Materials were obtained from Raven Industries (South Dakota), Charter Films (Wisconsin), and Lamart Corporation (New Jersey).

\section{References}

'Brown, R. (editor), Handbook of Polymer Testing, Marcel Dekker, New York, 1999.

${ }^{2}$ Nielsen, L.E., and Landel, R.F., Mechanical Properties of Polymers and Composites, $2^{\text {nd }}$ Ed., Marcel Dekker, New York, 1994.

${ }^{3}$ MIL-P-4640A (USAF), Military Specification, Plastic Film, Polyethylene, for Balloon Use, 17 June 1957. Superceding MIL-P-4640 (USAF), 5 September 1956.

${ }^{4}$ ASTM D882, Standard Test Method for Tensile Properties of Thin Plastic Sheeting, American Society for Testing and Materials, West Conshohocken, PA, 2002.

${ }^{5}$ ASTM D1922, Standard Test Method for Propagation Tear Resistance of Plastic Film and Thin Sheeting by Pendulum Method, American Society for Testing and Materials, West Conshohocken, PA, 2003. 
${ }^{6}$ ASTM D3420, Standard Test Method for Pendulum Impact Resistance of Plastic Film, American Society for Testing and Materials, West Conshohocken, PA, 1995.

${ }^{7}$ Smith, I.S., "Overview of the NASA Balloon R\&D Program," Adv. Space Res., V.14 (2), p. 137-146, 1994.

${ }^{8}$ Rainwater, E.L., Fairbrother, D.A., Smith, M.S., "Extended Capabilities of Zero-Pressure and Superpressure Scientific Ballooning Platforms", AlAA's $3^{\text {rd }}$ Annual Aviation Technology, Integration, and Operations (ATIO) Technical Forum, Paper No. 2003-6786, Denver, CO, 2003.

${ }^{9}$ Rainwater, E.L., Smith, M.S., "Ultra High Altitude Balloons for Medium-to-Large Payloads", $34^{\text {th }}$ Committee on Space Research Scientific Assembly (COSPAR), Paper No. PSB 1-0022-02, Houston, TX, 2002.

${ }^{10}$ Kerzhanovich, V.V., Cutts, J. A., Cooper, H.W., Hall, J.L., McDonald, B.A., Pauken, M.T., White, C.V., Yavrouian, A.H., Castano, A., Cathey, H.M., Fairbrother, D.A., Smith, I.S., Shreves, C.M., Lachenmeier, T., Rainwater, E., and Smith, M., "Breakthrough in Mars Balloon Technology", $34^{\text {th }}$ Committee on Space Research Scientific Assembly (COSPAR), Paper No. PSB 1-0076-02, Houston, TX, 2002. 